Int. J. Electrochem. Sci., 11 (2016) 9030 - 9040

\title{
Determination of Norepinephrine Tartrate at Oxidized Graphene Nanoribbon Modified Glassy Carbon Electrode
}

\author{
Y. Z. Song ${ }^{*}$, M.J.Yang, J. Yuan, X.L. Han \\ Huaiyin Normal University, Jiangsu Province Key Laboratory for Chemistry of Low-Dimensional \\ Materials, School of Chemistry \& Chemical Engineering, Huai An 223300, People's Republic of \\ China \\ *E-mail: songyuanzhi@126.com
}

doi: $10.20964 / 2016.11 .20$

Received: 19 November 2015 / Accepted: 28 August 2016 / Published: 10 October 2016

In this paper the oxidized graphene nanoribbons for a sensor were prepared with glassy carbon electrode, and the electrochemical behavior of norepinephrine tartrate at the modified electrode was studied. It was found that the norepinephrine tartrate at the oxidized graphene nanoribbon modified glassy carbon electrode can be catalyzed significantly. The proposed method was used for determination of norepinephrine tartrate injection. The linear range and limit of detection were $6.0 \times 10^{-}$ 6 - $7.6 \times 10^{-5}-1.5 \times 10^{-4} \mathrm{M}$ and $2.1 \times 10^{-8} \mathrm{M}$, respectively. The recoveries were in the range from 96.0 to $104.4 \%$ with $\mathrm{RSD}$ of $1.2 \sim 3.0 \%(\mathrm{n}=6)$ in the range of $0.0 \sim 50.0 \mathrm{mg} . \mathrm{L}^{-1}$. The recoveries were in the range from 96.0 to $104.4 \%$ with $\mathrm{RSD}$ of $1.2 \sim 3.0 \%(\mathrm{n}=6)$ in the range of $0.0 \sim 50.0 \mathrm{mg} . \mathrm{L}^{-1}$.

Keywords: oxidized graphene nanoribbons, norepinphrine tartrate, electrochemical sensor

\section{$\underline{\text { FULL TEXT }}$}

(C) 2016 The Authors. Published by ESG (www.electrochemsci.org). This article is an open access article distributed under the terms and conditions of the Creative Commons Attribution license (http://creativecommons.org/licenses/by/4.0/). 